\title{
Dificuldades no diagnóstico laboratorial das hemoglobinopatias ${ }^{1}$ Dificulties on the laboratorial diagnosis of hemoglobinopathies
}

Paulo Cesar Naoum ${ }^{2}$

Claudia R. Bonini-Domingos ${ }^{3}$
Há vários tipos de hemoglobinopatias que são caracterizados por variantes das hemoglobinas anormais (ex: $\mathrm{Hb} \mathrm{S}, \mathrm{Hb} C, \mathrm{Hb}$ Instáveis,etc) e por talassemias (ex: tal. alfa, tal. beta, tal.beta/delta,etc) As hemoglobinopatias são consideradas como uma das doenças genéticas mais comuns em todo o mundo, com prevalência de portadores heterozigotos de seus principais tipos em aproximadamente 5\% da população mundial. Devido à heterogenidade clínica e genética dessas alterações genéticas éfundamental estabelecer a investigação laboratorial das diferentes formas de hemoglobinas variantes e de talassemias. Este artigo apresenta as principais dificuldades laboratoriais que envolvem a complexidade molecular das hemoglobinopatias. Rev. bras. hematol. hemoter. 2007;29(3):226-228.

Palavras-chave: Hemoglobinopatias;talassemias; doença falciforme.

\section{Introdução}

Hemoglobinopatias é o nome dado aos grupos de doenças autossômicas recessivas que compreendem as talassemias, doença falciforme, hemoglobinas instáveis e hemoglobinas variantes com alterações funcionais. As talassemias são decorrentes do desequilíbrio das concentrações de globinas alfa e beta, afetadas durante seus processos de síntese, que diminuem ou suprimem a produção de globinas alfa ou beta que compõe o tetrâmero da molécula de hemoglobina. A diversidade das lesões genéticas que afetam as sínteses de globinas nos genes alfa e beta resultam a expressiva heterogeneidade clínica, celular e de resultados laboratoriais das talassemias. ${ }^{1} \mathrm{O}$ grupo da doença falciforme se caracteriza por diferentes genótipos bem definidos. Entretanto, a interação da $\mathrm{Hb} \mathrm{S}$ com talassemias alfa e beta, bem como com deficiência de enzimas eritrocitárias, notadamente a G-6PD, dificulta o diagnóstico laboratorial. As hemoglobinas instáveis, por sua vez, são díspares nas suas origens genéticas, nas evidências clínicas e nos resultados laboratoriais. Esse grupo de hemoglobinas, composto por variantes de globinas alfa e beta, com mutações em regiões sensíveis do tetrâmero molecular, é o que apresenta maior grau de complicação no diagnóstico laboratorial. As hemoglobinas variantes com alterações funcionais são aquelas que interferem no processo fisiológico da afinidade pelo oxigênio. Essas hemoglobinopatias se devem a trocas de aminoácidos em regiões que permitem a movimentação do tetrâmero durante a oxigenação, quais sejam, os contatos intermoleculares $\alpha^{1} \beta^{2}, \alpha^{2} \beta^{1}$ e $\beta^{1} \beta^{2}$, principalmente.

Por todas essas razões, as dificuldades para o diagnóstico laboratorial se apresentam quando não se dispõe de um ou mais ítens relacionados a seguir:

- conhecimento científico e técnico para efetuar o estudo das hemoglobinopatias;

- $\quad$ informações sobre a suspeita clínica do paciente;

- informações relativas ao eritrograma e, em especial, dos índices hematimétricos;

- possibilidade de realizar a repetição dos exames do paciente;

- possibilidade de realizar exames nos pais do paciente.

${ }^{1}$ Tema referente à apresentação realizada no I Encontro Brasileiro de Doenças Falciformes

${ }^{2}$ Professor titular pela Unesp. Academia de Ciência e Tecnologia de São José do Rio Preto, SP.

${ }^{3}$ Professora doutora pela Unesp. Departamento de Biologia, Instituto de Biociências. Letras e Ciências Exatas, Unesp de São José do Rio Preto, SP.

Correspondência: Paulo Cesar Naoum

Academia de Ciência e Tecnologia

Rua Bonfá Natale, 1.860

15020-130 - São José do Rio Preto-SP - Brasil

Tel.: (17) 3233-4490

E-mail: a.c.t@terra.com.br 


\section{Dificuldades no diagnóstico laboratorial das talassemias}

Talassemia alfa - A principal característica laboratorial da talassemia alfa é a visualização da $\mathrm{Hb} \mathrm{H}$ em amostras de sangue hemolisados com saponina a $1 \%$ e submetidas a eletroforese em acetato de celulose - o fundo branco deste tipo de eletroforese facilita a identificação da $\mathrm{Hb} \mathrm{H}$. A Hb H pode apresentar concentrações visíveis a partir de $0,5 \%$ a 1,0\%. Geralmente, portadores de Hb H com concentração entre $0,5 \%$ e 2,0\% não mostram alterações numéricas no eritrograma. Por outro lado, portadores de $\mathrm{Hb} \mathrm{H}$ com concentrações entre 3,0\% e 7,0\% apresentam eritrograma típico de talassemia menor, com eritrocitose em relação do hematócrito e índices VCM e HCM reduzidos. A doença de Hb H, entretanto, é de fácil diagnóstico, pois a concentração da Hb H é sempre maior que $15 \%$ e o eritrograma exibe expressivas alterações morfológicas associadas a moderado grau de anemia. As dificuldades se apresentam principalmente devido à imperícia técnica, seguida de situações específicas, por exemplo: na interação alfa/beta talassemia, desequilíbrio entre globinas alfa e beta pode ser mínimo e, dessa forma, a $\mathrm{Hb} \mathrm{H}$ se torna indetectável por eletroforese ou na pesquisa citológica com azul de crezil brilhante. ${ }^{2}$

Talassemia beta menor - Em 90\% dos portadores de talassemia beta menor, a concentração da $\mathrm{Hb} \mathrm{A}_{2}$ apresentase elevada (>4\%-7\%), com eritrograma composto por eritrocitose em relação ao hematócrito, índices VCM e HCM reduzidos, morfologia eritrocitária com presença de micrócitos esquisócitos, dacriócitos, hipocromia e pontilhados basófilos. A principal dificuldade ocorre pela concentração "normal" de $\mathrm{Hb} \mathrm{A}_{2}$ decorrente da associação com anemia ferropênica - a baixa concentração de ferro interfere na síntese de globina delta, diminuindo a síntese da $\mathrm{Hb} \mathrm{A}_{2}$. Uma outra situação é a interação da talassemia beta menor com talassemia alfa, fato que diminui o desequilíbrio entre globinas alfa e beta e, por essa razão, a $\mathrm{Hb} \mathrm{A}_{2}$ pode-se apresentar em níveis normais e a $\mathrm{Hb} \mathrm{H}$ tornar-se visualmente imperceptível. Há casos em que o portador de talassemia beta menor apresenta aumento das concentrações de $\mathrm{Hb} \mathrm{A}_{2}$ e de $\mathrm{Hb}$ fetal (> 2\% a 5\%), ou então com nível normal de $\mathrm{Hb} \mathrm{A}_{2}$ e $\mathrm{Hb}$ fetal elevada (> 2\% a 5\%). ${ }^{2}$

Talassemia beta maior - Laboratorialmente, o paciente com talassemia beta maior apresenta anemia grave com exuberante alteração da morfologia eritrocitária. A análise eletroforética revela elevada concentração de Hb Fetal entre $20 \%$ e $100 \%$ dependendo do tipo genético da talassemia beta. A maior dificuldade se deve à análise de sangue de pacientes transfundidos recentemente, bem como à dificuldade de se realizarem exames nos pais antes de emitir o laudo definitivo. A despeito dessas dificuldades, a talassemia beta maior é de fácil diagnóstico laboratorial. ${ }^{2}$

\section{Dificuldades no diagnóstico da doença falciforme}

A síndrome falcêmica impõe o correto diagnóstico clínico, fundamentado no diagnóstico laboratorial. Os diferentes tipos de associação genética da $\mathrm{Hb} \mathrm{S}$, com destaque para a homozigose ou Hb SS, interação com talassemia beta ou $\mathrm{Hb}$ S/Beta Tal., interação com talassemia alfa ou $\mathrm{Hb} \mathrm{SH}$, e as duplas heterozigoses, Hb SC e Hb SD, principalmente, necessitam de métodos complementares (eletroforese em agarácido, dosagem de $\mathrm{Hb}$ Fetal, pesquisa de $\mathrm{Hb} \mathrm{H}$, etc) e, em especial o eritrograma. A maior dificuldade é observada quando a eletroforese fraciona a $\mathrm{Hb} \mathrm{S}$ com $\mathrm{Hb}$ Fetal elevada (ex.: $15 \%$ de Hb Fetal), caracterizando a Hb SF. Nesses casos, a Hb Fetal elevada pode estar relacionada a uma dessas três causas: persistência hereditária de Hb Fetal associada à anemia falciforme; Hb Fetal elevada devido ao tratamento com hidroxiuréia em paciente com anemia falciforme; interação $\mathrm{Hb}$ S/Beta talassemia. Nas duas primeiras causas os índices hematimétricos VCM e HCM geralmente estão normais e, em especial, na Hb S/Persistência Hereditária de Hb Fetal, a hemoglobina total está geralmente nos parâmetros normais, enquanto na anemia falciforme com Hb Fetal elevada devido ao tratamento com hidroxiuréia há muita variação no nível de hemoglobina. Por outro lado, a interação Hb S/Beta talassemia mostra diminuição dos índices VCM e HCM. Portanto, as dificuldades se devem ao desconhecimento por parte do laboratório do uso da medicação hidroxiuréia pelo paciente, bem como da possibilidade de não ter os índices hematimétricos à disposição para completar a análise laboratorial. Para essas três situações expostas, as dificuldades diminuiriam se fosse possível realizar os exames dos pais. ${ }^{3}$

A definição do provável diagnóstico laboratorial das doenças falciformes, estabelecidas com base em procedimentos eletroforéticos, análise do eritrograma e morfologia eritrocitária, pode ser completada pelas avaliações quantitativas das frações de hemoglobinas e perfil cromatográfico, com rapidez e segurança, pela Cromatografia Líquida de Alta Perfomance - HPLC. A combinação desses resultados laboratoriais define condutas metodológicas pré-moleculares e afastam as interações com as hemoglobinas similares à $\mathrm{Hb}$ S, como são os casos da Hb D, Hb Korle-Bu, Hb G, etc. ${ }^{4}$

Baseados nesses resultados em conjunto, o possível mutante será avaliado quanto à sua viabilidade de identificação, por bioinformática, estabelecendo os indicadores que melhor se adequem às condições de amplificação do alelo e estratégia de visualização. Ressaltamos que a qualidade do material genômico a ser analisado é fundamental, e um bom método de extração e purificação deve ser escolhido segundo as condições das amostras sangüíneas. Após a amplificação do alelo, a identificação do mutante poderá incluir análise de fragmentos de digestão por enzimas específicas, gerando resultados diferentes para homozigotos e heterozigotos para a hemoglobina em questão. 
A PCR-AE - amplificação alelo-específica - consiste somente na amplificação dos alelos mutantes e normais, facilitando a análise e diminuindo custos, por não utilizar enzimas de restrição.?

O conjunto de resultados laboratoriais, tanto das metodologias clássicas, quanto das moleculares, contribuem para o conhecimento das hemoglobinas no Brasil, elucidando interações e auxiliando na orientação genético-educacional

\section{Dificuldade no diagnóstico das hemoglobinas instáveis}

A grande maioria das hemoglobinas instáveis descritas se devem a trocas de aminoácidos neutros, ex: prolina por treonina, tirosina por leucina, etc. Essas substituições de aminoácidos não causam alterações de cargas elétricas e, portanto, não alteram o ponto isoelétrico da hemoglobina mutante. Por essa razão, dificilmente as hemoglobinas instáveis apresentam posições eletroforéticas ou cromatográficas diferentes da $\mathrm{Hb}$ A. Entretanto, cerca de 80\% apresentam metaemoglobinemia e corpos de Heinz. O teste específico é a desnaturação térmica a $50-55^{\circ} \mathrm{C}$, fato que induz a precipitação da Hb instável. Outra informação importante é a presença de globinas alfa, próximo à aplicação da amostra, nas hemoglobinas instáveis mutantes de globina beta. É fundamental para o diagnóstico das hemoglobinas instáveis as informações clínicas do paciente, com destaque para processo hemolítico. O eritrograma mostra anemia variável entre discreta e acentuada, VCM normal ou diminuído, HCM sempre diminuído, morfologia eritrocitária com presença de células mordidas e reticulocitose moderada a acentuada. ${ }^{2}$

\section{Dificuldades no diagnóstico das hemoglobinas com alterações funcionais}

As alterações funcionais das hemoglobinas se devem estritamente às hemoglobinas com afinidade aumentada ao oxigênio e às que se transformam naturalmente em metaemoglobina. Há cerca de quarenta tipos diferentes de hemoglobinas com afinidade aumentada ao oxigênio, e a maioria tem como característica a eritrocitose elevada em conjunto com o aumento do hematócrito e hemoglobina (g/dL). Das principais hemoglobinas variantes com alterações funcionais, 60\% migram na posição de $\mathrm{Hb} \mathrm{A}$, pois as trocas de aminoácidos não envolvem diferença de cargas elétricas; $20 \%$ migram em posições intermediárias entre a Hb A e Hb S; 15\% são mais rápidas que a $\mathrm{Hb}$ A e se situam próximo à posição de Hb J e 5\% migram na posição padrão da Hb S. Dessa forma, as dificuldades de interpretação por meio de eletroforeses são enormes. A curva de equilíbrio de oxigênio obtida pela avaliação do grau de saturação da hemoglobina em relação a pressões definidas de oxigênio é ainda a melhor metodologia convencional para um diagnóstico laboratorial rápido e eficiente. Por outro lado, os diferentes tipos de metaemoglobinas conhecidas por Hb M são identificados por absorção espectrofotométricas específicas e dosagem de metaemoglobina. A dificuldade do diagnóstico por meio da eletroforese se deve ao fato da fração de metaemoglobina migrar muito próximo da Hb A. Funcionalmente, a afinidade da hemoglobina por oxigênio pode estar normal (ex: Hb M Milwakee), diminuída (ex: Hb M Boston e Hb M Iwate), ou aumentada (ex: Hb Saskatoon). Além disso, algumas são instáveis (ex: Hb Hyde Park e Hb Saskatoon) associada à anemia hemolítica. Por essas razões, as dificuldades técnicas para o diagnóstico laboratorial se tornam complexas devido à necessidade da utilização de vários métodos associados às informações clínicas dos pacientes. ${ }^{2}$

\begin{abstract}
There are various types of hemoglobinopathies that are characterized by variants of abnormal hemoglobins (eg. $\mathrm{Hb} \mathrm{S}, \mathrm{HbC}$, unstables $\mathrm{Hb}$, etc.) and thalassemias (eg. alpha, beta, beta/delta, etc.). Hemoglobinopathies account for some of the most common single gene disorders worldwide with at least $5 \%$ of the world's population having one or more serious genetic abnormalities. Because of the clinical and genetic heterogenity of these disorders, a laboratory investigation is fundamental to establish the diagnosis of the different variants of the abnormal hemoglobinopathies and thalassemias. This article reports on the laboratory diagnostic difficulties caused by molecular complexity of these abnormalities. Rev. bras. hematol. hemoter. 2007;29(3):226-228.
\end{abstract}

Key words: Hemoglobinopathies; thalassemias; sickle cell disease.

\section{Referências Bibliográficas}

1. Weatherall DJ. The molecular basis of phenotipic variability of common thalassaemias. Molecular Medicine Today. 1995;1:15-20.

2. Naoum PC. Hemoglobinopatias e talassemias. Ed. Sarvier, São Paulo, 1997, $171 \mathrm{p}$.

3. Naoum PC, Naoum FA. Doença das Células Falciformes. Ed. Sarvier, São Paulo, 2004, 220 p.

4. Bonini-Domingos CR, Ondei LS, Zamaro PJA. Hemoglobinas similares a S: Um guia prático de identificação. São José do Rio Preto: HN, 2006.

5. Ondei LS, Zamaro PJA, Bonini-Domingos CR. A importância do diagnóstico laboratorial clássico na identificação de variantes de hemoglobinas. Rev. bras. hematol. hemoter. 2005;27(1):72-4.

6. Fernandes ARC, Bonini-Domingos CR. Contribuição do estudo molecular de hemoglobina S-like para o conhecimento da diversidade genética da população brasileira. Rev. bras. hematol. hemoter. 2005;27(3):208-12.

7. Fernandes ARC, Mendiburu CF, Bonini-Domingos CR. Utilization of different methodologies for characterization of Hb Hasharon heterozygotes. Genetics and molecular research. 2006;5(1):1-6.

O tema apresentado e o convite aos autores constam da pauta elaborada pelo co-editor, prof. Rodolfo Delfini Cançado.

Avaliação: Co-editor e um revisor externo.

Publicado após revisão e concordância do editor.

Conflito de interesse: não declarado.

Recebido: 03/06/2007

Aceito: 18/08/2007 